\title{
A common enzyme connects Notch signaling and Alzheimer's disease
}

\author{
Raphael Kopan ${ }^{1}$ and Alison Goate \\ Department of Pharmacology and Molecular Biology, Departments of Psychiatry and Genetics, Washington University \\ School of Medicine, St. Louis, Missouri 63110, USA
}

Biology in its broadest sense is a multifaceted endeavor aimed at solving a puzzle with a finite, but extremely large, number of pieces. Often it is hard to predict how wide the gap separating two individual bits of knowledge within the larger picture would be. Therefore, when researchers working in diverse fields simultaneously realize that their fragments of the puzzle fit together, what appeared as an insurmountable distance is bridged rapidly as the remaining pieces are fitted into place. Several studies published recently by developmental biologists, neuroscientists, and researchers who are interested in the identification of therapeutic targets and treatments for Alzheimer's disease (AD) have tied together diverse phenomena into one coherent paradigm. As a result, a new signal transduction paradigm has emerged (Brown et al. 2000; Mumm et al. 2000) that is shared by Notch, lipid-sensing mechanisms in the cell, possibly the unfolded protein response (UPR), and a proteolytic pathway that is central to the pathogenesis of $\mathrm{AD}$. The culmination of these observations is four papers that were published this summer that provide compelling evidence for the existence of a novel class of enzymes (Esler et al. 2000; Li et al. 2000a,b; Seiffert et al. 2000). These enzymes are polytopic membrane proteins that are capable of catalyzing the intramembranous hydrolysis of a peptide bond. The founding members of this class of proteases are the presenilin proteins (PS).

\section{PS are conserved proteins}

PS are found primarily within intracellular membranes, including the endoplasmic reticulum (ER) and the transGolgi network as well as the plasma membrane (Selkoe 1998; Ray et al. 1999a). PS are also expressed in most cell types throughout development. In mammals there are two PS genes, referred to as PS1 and PS2, that share $65 \%$ identity. The spatial patterns of expression of PS1 and PS2 are overlapping, but PS1 is expressed at a higher level during early development than is PS2 (Lee et al. 1996; Berezovska et al. 1997). Because no detailed developmental analysis of the temporal and spatial patterns of

${ }^{1}$ Corresponding author.

E-MAIL kopan@molecool.wustl.edu; FAX (314) 362-7058.

Article and publication are at www.genesdev.org/cgi/doi/10.1101/ gad.836900. expression of the PS genes has been conducted, it is difficult to explain why PS1 deficiency in mice is embryonic lethal, whereas PS2-deficient mice show no obvious phenotype. There is, however, some functional redundancy, as the PS1 null (Shen et al. 1997; Wong et al. 1997) is not as severe as the combined PS1 and PS2 null (see below; Donoviel et al. 1999; Herreman et al. 1999). Sequence alignments have identified PS homologs in species as diverse as Drosophila melanogaster, Caenorhabditis elegans, and Arabidopsis thaliana, but not in yeast (Sacchromyces cerevisiae). Indeed, human PS can rescue C. elegans mutants that carry a mutation in Sel-12, one of the nematode PS homologs that shows functional and sequence homology (Levitan et al. 1996; Baumeister et al. 1997). The primary sequence of PS has 10 hydrophobic regions (HRs); experimental evidence suggests a protein that has six to eight (Doan et al. 1996; Li and Greenwald 1996; Lehmann et al. 1997; Nakai et al. 1999) transmembrane (TM) domains. A large cytoplasmic loop is postulated between TM6 and TM7. This loop contains a HR that does not appear to traverse the membrane but is likely to be membrane associated (Fig. 1; Li and Greenwald 1996, 1998; Nakai et al. 1999).

PS are synthesized as a single polypeptide (FL-PS) that rapidly undergoes endoproteolysis within the cytoplasmic loop, generating two stable fragments (NTF and CTF) that associate in a high-molecular-weight complex with other proteins that can include $\beta$-amyloid precursor protein (APP), Notch, and $\beta$-catenin (Haass and Baumeister 1999; Selkoe 1999; Yu et al. 2000a). PS endoproteolysis is tightly regulated such that overexpression of PS leads to the appearance of full-length PS, but does not result in an increase in the levels of the fragments (Thinakaran et al. 1996). The overexpressed protein gradually replaces the endogenous pool of PS fragments. This observation contributed to the hypothesis that the cleaved form of PS represents the functional molecule.

\section{APP and the production of $\beta$-amyloid}

Mutations in PS1 and PS2 are the most common known cause of autosomal dominant familial Alzheimer's disease (FAD; for review, see Lendon et al. 1997; Ray et al. 1998). More than 75 FAD mutations have been reported in PS1, whereas only eight FAD mutations have been 


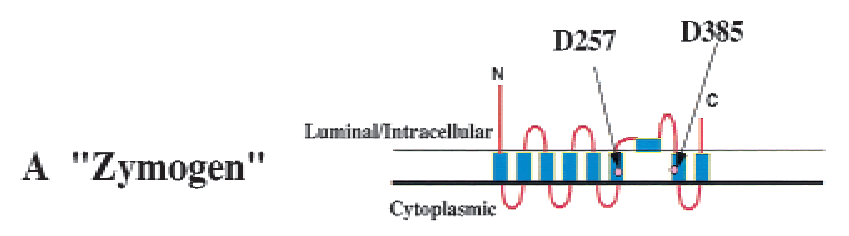

\section{B " $\gamma$-secretase"}
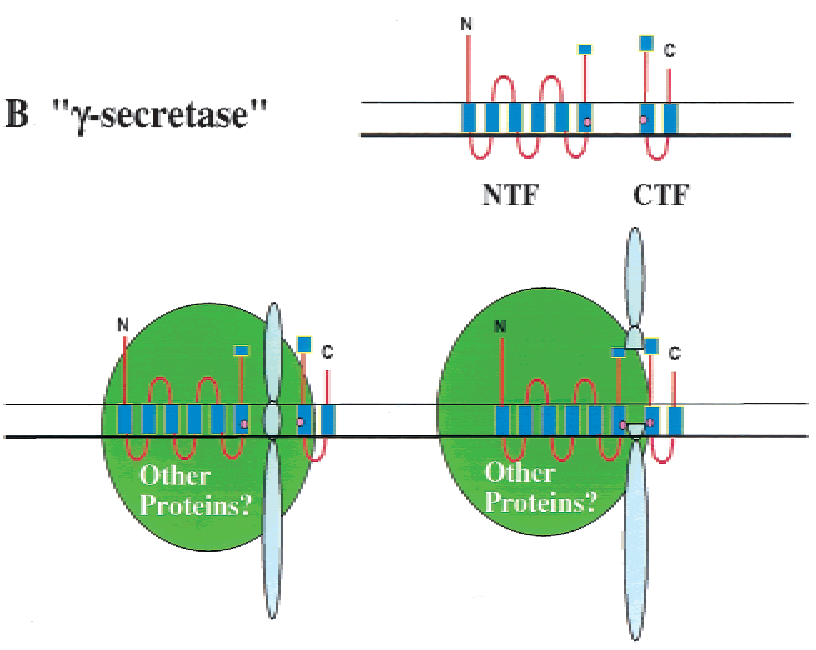

Figure 1. A speculative representation of the $\gamma$-secretase complex. Endoproteolysis is required to convert presenilins (PS) from a zymogen $(A)$ to the active enzyme $(B)$. A multiprotein complex, of which PS is an obligatory component, forms $\gamma$-secretase $(B)$. The identity of the proteins within the complex is unknown. (The dependence of Notch and APP cleavage on a preceding ectodomain shedding is not reflected in the illustration.) (For additional details, see text and the references within.)

reported in PS2 (http://www.alzforum.org). The mutations in PS1 are located primarily within the TM domains and in the $\mathrm{N}$-terminal portion of the cytoplasmic loop, close to the endoproteolytic cleavage site. All mutations analyzed to date increase levels of $A \beta 42$, the primary species of $A \beta$ deposited in senile plaques (Selkoe 1999|. These mutations affect the metabolism of the APP, a type I TM protein that is the precursor of the $\beta$-amyloid $(A \beta)$ peptides that aggregate in senile plaques in AD (for a review of APP metabolism, see Selkoe 1999; De Strooper and Annaert 2000). The $N$ terminus of $A \beta$ is generated when the APP ectodomain is released by $\beta$-secretase, producing a 99-amino-acid membrane-associated C-terminal fragment (C99; Selkoe 1999). C99 is then a substrate for $\gamma$-secretase, the enzymatic activity (or activities) that generates the $\mathrm{C}$ terminus of $\mathrm{A} \beta$ by cleaving at one of several positions within the TM domain. $\gamma$-secretase cleavage releases $A \beta$ peptides that are predominantly 40 amino acids long (A $\beta 40)$, but also include longer species of 42 or 43 residues (A $\beta 42)$. FAD mutations in APP are clustered within the A $\beta$ sequence and around the proteolytic cleavage sites that release $A \beta$ (Ray et al. 1998). These mutations also lead to elevated levels of $A \beta 42$, which suggests that this change in APP metabolism is central to AD pathogenesis (the " $\beta$-amy- loid hypothesis"). The APP ectodomain can also be released into the extracellular space by another activity (or activities), $\alpha$-secretase, generating a smaller membraneassociated fragment (C83). C83 is also a substrate for $\gamma$-secretase, but the resulting $\mathrm{N}$-terminal product (called p3) does not contain the complete $A \beta$ region.

Expression-cloning studies have recently shown that $\beta$-secretase is a novel membrane-associated aspartyl protease that has been termed BACE or Asp2 (Hussain et al. 1999; Sinha et al. 1999; Vassar et al. 1999; Yan et al. 1999; Lin et al. 2000). $\alpha$-Secretase activity shows both constitutive and regulated cleavage (by protein kinase C) of APP. Preliminary studies suggest that two metalloproteases, tumor necrosis factor $\alpha$ converting enzyme (TACE or ADAM-10) and Kuzbanian (ADAM-17) possess $\alpha$-secretase activity (Buxbaum et al. 1998; Lammich et al. 1999). Inhibitor studies have shown that $\gamma$-secretase has pharmacological properties of an aspartyl protease (Wolfe et al. 1998).

The function and the purpose of the extensive proteolytic processing of APP remain a mystery. Although it was originally thought to be a receptor, no ligand for APP has yet been identified. APP-deficient mice are viable with no obvious phenotype. This is likely to be attributable to the presence of two APP homologs in mammals, APLP1 and APLP2 (von Koch et al. 1997). The A $\beta$ region of APP is poorly conserved in these homologs, which suggests that $A \beta$ is not essential to APP function. However, both homologs do undergo proteolytic cleavage, which results in ectodomain shedding.

Analysis of PS1-deficient animals has revealed that PS1 is required for the $\gamma$-secretase processing of APP and the APLPs (De Strooper et al. 1998; Naruse et al. 1998). Levels of $A \beta$ are dramatically reduced in these mice and the $\gamma$-secretase substrates accumulate. In contrast, $A \beta$ levels are normal in neurons from PS2-deficient mice. However, in PS1/PS2 double knock-out cells there is no detectable $A \beta$, indicating that there is no PS-independent $\gamma$-secretase activity (Herreman et al. 2000; Zhang et al. 2000).

\section{PS in Notch signaling}

The role of PS in Notch signaling was first revealed when loss of Sel-12, a presenilin homolog from C. elegans, was shown to suppress an activating point mutation in the Notch homolog Lin-12 (Levitan and Greenwald 1995). Notch loci, first described in Drosophila (for a historical perspective, see Wu and Rao 1999), code for a family of large ( 2500 amino acids) type I TM receptors with an extracellular domain containing $\leq 36$ EGF repeats and a membrane-proximal, cysteine-rich region (Lin Notch repeats, LNR). The Notch intracellular domain (NICD) features nuclear localizing signals, a multitude of protein-protein interaction domains (including Ankyrin repeats, found in both nuclear factors and cytoskeletal interacting proteins) and a C-terminal cluster of charged amino acids (PEST and OPA repeats) that are often found in transcription factors. Notch receptors are activated by type I TM ligands known collectively as DSL proteins (Delta, Serrate and Lag 2) and are therefore involved in 
receiving short-range signals. Notch is a "dual address" protein that contains two intrinsic signals. The first directs it to the cell surface where, in response to ligand binding, Notch undergoes intramembranous proteolysis. Proteolysis releases the NICD, which carries a second intrinsic signal and results in transport to the nucleus where it interacts with a CSL protein $(\underline{C B F}, \underline{\mathrm{Su}}(\mathrm{H})$, and Lag 1; for review, see Mumm and Kopan 2000). Notchmediated signals permit equivalent cells to acquire the proper fate during development and in adult tissues in many metazoans (for review, see Artavanis-Tsakonas et al. 1999; Milner and Bigas 1999). Notch receptors are cleaved between $\mathrm{Gly}^{1743}$ and $\mathrm{Val}^{1744}$ (Schroeter et al. 1998 ) at a site (termed site 3 or S3) that lies near the cytoplasmic side of the lipid bilayer (Schroeter et al. 1998; J.S. Mumm and R. Kopan, unpubl.). Proteolysis is regulated by ligand binding (Schroeter et al. 1998; Mumm et al. 2000). Nuclear access of NICD occurs in a ligand-dependent manner in Drosophila, presumably via proteolysis (Kidd et al. 1998; Lecourtois and Schweisguth 1998; Struhl and Adachi 1998). The importance of proteolysis for Notch signaling is shown by a new hypomorphic allele of Notch1. A Notch1 allele with a single point mutation at the S3 site that significantly reduced proteolysis in cultured cells (V1744G), was homologously "knocked-in" to the Notch1 locus. Mice that are homozygous for this allele display all the phenotypes seen in Notch-null embryos, albeit some with variable penetrance (Huppert et al. 2000).

Genetic analysis of gain-of-function Notch alleles has resulted in the hypothesis that the membrane proximal region, which contains the LNRs and the two conserved cysteines, negatively regulates S3 cleavage (Greenwald 1994). Active Notch molecules that contain mutations in this region or that contain sequence other than Notch at the extracellular surface reveal the appearance of a novel proteolytic fragment. Peptide sequencing shows that cleavage occurs between $\mathrm{Ala}^{1710}$ and $\mathrm{Val}^{1711}$ residues, $\sim 12$ amino acids outside the TM domain (at site 2 or S2). This same peptide bond is cleaved in vitro by the metalloprotease TACE ( $\alpha$-secretase; Brou et al. 2000). The product of this Notch extracellular truncation (NEXT) is an intermediate, much like activated Notch proteins that lack the extracellular domain $\left(\mathrm{N}^{\Delta \mathrm{E}}\right)$. NEXT is a substrate for the proteolytic apparatus that cleaves within the TM domain. Biochemical observations thus posit that a proteolytic cascade regulates this intramembranous cleavage (Mumm et al. 2000). This sequence of events is reminiscent of APP proteolysis: $\beta / \alpha$-secretase cleavage precedes $\gamma$-secretase cleavage.

Notch, like APP, interacts physically with PS1 (Ray et al. $1999 \mathrm{~b}$ ) and is found in a complex at the cell surface (Ray et al. 1999a). Several groups have shown the importance of PS proteins for intramembranous proteolysis of Notch1 (De Strooper et al. 1999; Song et al. 1999; Struhl and Greenwald 1999). In cells that lack both PS proteins, no $\gamma$-secretase activity is observed and $\mathrm{N}^{\Delta \mathrm{E}}$ is no longer able to signal (Herreman et al. 2000; Zhang et al. 2000). Of particular interest is the ability of $\gamma$-secretase inhibitors, designed to mimic the APP cleavage site, to block APP and Notch proteolysis with an identical IC-50 (De Strooper et al. 1999), which suggests that a common activity mediates the proteolysis of both proteins. In addition, the phenotype of total loss of PS genes in C. elegans (Li and Greenwald 1997; Westlund et al. 1999), mice (Donoviel et al. 1999; Herreman et al. 1999), and Drosophila (Struhl and Greenwald 1999; Ye et al. 1999) bears a striking resemblance to the phenotype of complete loss of Notch signaling (Oka et al. 1995; de la Pompa et al. 1997). Although most research has focused on the role of PS in Notch1 cleavage, all members of the Notch family of proteins undergo PS-dependent cleavage (M.T. Saxena and R. Kopan, unpubl.).

\section{PS in the UPR}

The UPR mediates a cellular response to stress in the ER by regulating transcription of target genes. ER stress often involves the accumulation of unfolded proteins, and UPR targets include ER-resident chaperone proteins and proteins involved in ER-associated protein degradation (Friedlander et al. 2000; Travers et al. 2000). UPR can also induce apoptosis in mammalian cells (Wang et al. 1998). Interestingly, PS1 may be required for a normal UPR; uncleaved PS1 interacts physically with Irelp, a mammalian homolog of a TM kinase/endoribonuclease sensor of ER stress in yeast (Katayama et al. 1999). FADassociated mutations in PS1 lead to a reduction in Ire1p phosphorylation, which in turn reduces Irelp-mediated activation of the chaperone GRP78/Bip. An alternative explanation for the involvement of PS1 in UPR is provided by Niwa et al. (1999). They report that C-terminal fragments of Ire1p enter the nucleus in a PS1-dependent manner in mammalian cells. Although the biochemical evidence presented is incomplete, this intriguing hypothesis may add Ire1p to the growing list of PS1-dependent, $\gamma$-secretase substrates. However, these observations remain controversial because others have failed to observe any effect on UPR in PS1/PS2-double null cells or in cells expressing PS1-FAD mutations (Sato et al. 2000).

Despite the wealth of evidence implicating PS in Notch and APP cleavage events, one important question remained unsolved by these studies: What is the precise role of PS in these proteolytic events? Are PS members of a new class of proteases that hydrolyze peptide bonds embedded within a membrane (Wolfe et al. 1999a,b,c) or are they involved in trafficking of $\gamma$-secretase substrates to the site of cleavage (Nishimura et al. 1999) or in presentation of substrates to $\gamma$-secretase?

\section{PS are $\gamma$-secretases}

Recent work has suggested that PS may be a novel class of aspartyl protease in which the catalytic aspartyl residues are embedded in the membrane and are contained on separate proteolytic fragments of the mature protein (Wolfe et al. 1999c). Mutation of either of two aspartyl residues, predicted to be embedded in TM domains 6 and 7 based on the model proposed by $\mathrm{Li}$ and Greenwald (1996), inhibits endoproteolysis and leads to a loss of PS 
function (Ray et al. 1999a; Steiner et al. 1999; Wolfe et al. 1999c). The next significant step came when Li et al. (2000a) successfully solubilized $\gamma$-secretase from HeLa cells. They discovered that the soluble activity was inhibited by the same high-affinity inhibitors as the cellular $\gamma$-secretase. Gel exclusion chromatography revealed that the $\gamma$-secretase activity eluted as a macromolecular complex with an apparent molecular weight of $2 \times 10^{6}$ daltons. The $\gamma$-secretase activity coeluted with soluble heterodimeric PS1. Moreover, $\gamma$-secretase activity coimmunoprecipitated with PS1 from the soluble extract. Importantly, the immunoprecipitated activity generated the same $A \beta 40$ to $A \beta 42$ ratio as the cellular activity, arguing that a single, multiprotein complex is able to hydrolyze residues at both sites. This appears to contradict an earlier finding that cleavage at $A \beta 40$ shows a different inhibitor sensitivity to cleavage at A $\beta 42$. Copurification of PS1 and $\gamma$-secretase activity suggests that PS is a critical constituent of the $\gamma$-secretase complex (Wolfe et al. 1999c; Li et al. 2000a), present at the site and time of substrate cleavage (Ray et al. 1999a). However, there was no biochemical evidence that PS1 contains the catalytic center of $\gamma$-secretase.

Using conceptually similar approaches, three groups have now provided this evidence (Esler et al. 2000; Li et al. 2000b; Seiffert et al. 2000). All groups modified their $\gamma$-secretase inhibitors to allow photoactivated covalent cross-linking to the enzyme. Biotin tagged inhibitor and ${ }^{3} \mathrm{H}$-labeled inhibitors were used to allow identification of $\gamma$-secretase (for details of the chemical structure, see Esler et al. 2000; Li et al. 2000b; Seiffert et al. 2000). Using transition state analogs, which should bind to the active site of $\gamma$-secretase, Li et al. (2000b) biotinylated inhibitors that bound specifically and exclusively to the CTF of PS1 and PS2 in solubilized $\gamma$-secretase. By reversing the position of the photoactivated cross-linker group, PS1 NTF could also be labeled. The biotinylated inhibitors labeled full-length protein only in cells expressing the FAD associated PS $\triangle \mathrm{E}$ 9, a functionally active variant of PS that lacks exon 9 and does not undergo endoproteolysis. The failure of these inhibitors to label full-length
PS suggests that active, solubilized $\gamma$-secretase is the heterodimeric form of PS, and that the full-length form is a zymogen (see also, Yu et al. 2000a). Esler and colleagues (2000) made similar observations with a transition-state analog generated from a substrate-based lead. The DuPont group (Seiffert et al. 2000), following a screen lead, used a benzophenone analog of a ${ }^{3} \mathrm{H}$-labeled $\gamma$-secretase inhibitor derived from succinate and identified the specifically cross-linked polypeptides by immunoprecipitation, using antibodies to PS1 and PS2. Specific crosslinking was observed to the $\mathrm{N}$ - and C-terminal fragment of PS1 and to the C-terminal fragment of PS2. Because three different chemistries labeled heterodimeric PS specifically, these results strongly support the hypothesis that $\gamma$-secretase activity is intrinsic to the PS proteins (Fig. 1).

Although both PS1 and PS2 appear to be $\gamma$-secretases it is not clear whether the two enzymes normally have similar or distinct substrates in vivo, as they reside in different complexes (no detectable PS2 was coimmunoprecipitated with PS1 by using anti-PS1-NTF antibody; Y. Li, pers. comm.). The expression pattern of PS1 and PS2 is broad and shows considerable overlap, which suggests that the two enzymes may have distinct substrate or sequence preferences rather than performing the same cleavages in different tissues or cellular locations.

This rapid rate of discovery culminated with the definition of the PS1 active site, centered around a glycineaspartyl pair in the putative TM domain 7 (G/AX' GDX $^{\prime \prime}$ where $\mathrm{X}^{\prime}$ is not conserved and $\mathrm{X}^{\prime \prime}$ is hydrophobic; the site in TM6 is less well defined; H. Steiner and C. Haass, pers. comm.; Fig. 2). This observation enabled the investigators to perform a database search and to identify a family of bacterial membrane-bound type 4 prepilin peptidases (TFPP; LaPointe and Taylor 2000), polytopic membrane proteins with an active site containing the consensus G/AX' $\underline{G D X}{ }^{\prime \prime}$. Thus, PSs belong to a large family of nonconventional aspartyl proteases (Fig. 2).

The emerging class of intramembrane-cleaving proteases (I-CLiPs; Wolfe et al. 1999a) includes other proteins. $\mathrm{S} 2 \mathrm{P}$, a polytopic membrane protein that regulates cho-

Figure 2. A hypothetical "founding class" of intramembrane-cleaving proteases (I-CLiPs). Depicted at left are KyteDoolittle hydropathy plots, on the right are speculative structures. Proteins are not drawn to scale. On each plot the putative catalytic center is marked with arrows. The diaspartyl proteases (red transmembrane [TM] domains) presenilin (PS) and TFPP and the $\mathrm{Zn}^{++}$coordinating protease (green TM domains) S2P represent vertebrate and bacterial members of their respective families. (Details about the PS and TFPP are in the text; for S2P, see Brown et al. 2000.) Note that the active center of each protein is present in different TM domains that are predicted to

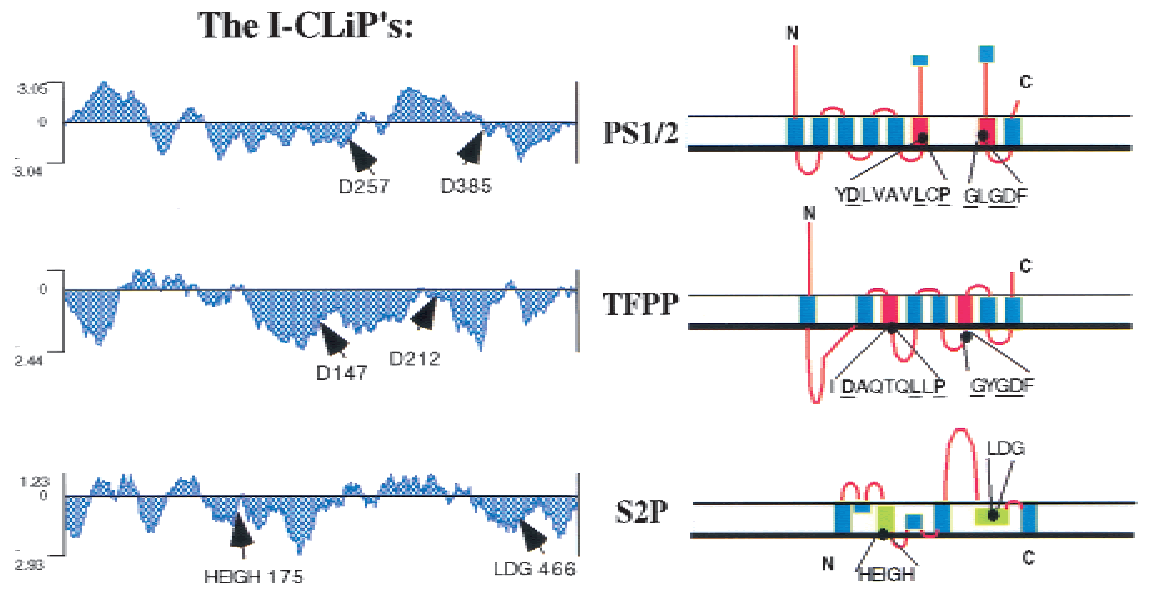
come closer together in the folded protein. Also, at least one half of the center is embedded in the middle of a hydrophobic domain, possibly within the lipid bilayer for PS and S2P but not for TFPP which therefore may not be an I-CLiP. 
lesterol metabolism by intramembranous cleavage of the sterol regulatory element-binding protein (SREBP), was, in fact, the first documented intramembrane protease. Cleaved SREBP releases a fragment containing a basichelix-loop-helix motif that translocates to the nucleus and modifies gene expression by directly binding to cognate sites. Although it performs a similar function to PS, S2P shares no sequence similarity with PS and, indeed, is a metalloprotease rather than an aspartyl protease (Fig. 2; for review, see Brown et al. 2000).

\section{Unresolved issues}

How do enzymes hydrolyze peptide bonds in an apparently hydrophobic environment and what regulates cleavage? Models have been proposed postulating that the multiple hydrophobic domains found in PS and S2P may serve to create a water channel around the substrate, relaxing the $\alpha$-helical structure of its TM domain and exposing the peptide bond to hydrolysis (Wolfe et al. 1999a). Another possibility may be that the intracellular domains of Notch and APP may assume a nonhelical conformation that is supported by hydrogen bonds with side chains present in the TM domains of PS protein or other members of the high-molecular-weight complex. The key to the regulation of cleavage may lie in the characterization of other proteins that are present in the high-molecular-weight complex that contains $\gamma$-secretase activity. The high-molecular-weight complexes have been shown to contain, in addition to PS, several substrates of $\gamma$-secretase as well as $\beta$-catenin. Although $\beta$-catenin binds PS, it is not thought to undergo proteolytic cleavage by PS. The possibility that $\beta$-catenin may regulate PS activity in some way has not been explored. However, considering the reported changes in Irelp phosphorylation in FAD PS-expressing cells (Katayama et al. 1999), PS proteins may be multifunctional and their interactions with $\beta$-catenin may involve this other hypothetical activity.

Each PS protein resides within its own complex and possibly associates with its own adapters. Furthermore, adapters may recognize specific substrates. This possibility may explain another observation that arises from the characterized cleavage sites attributed to $\gamma$-secretase activity. Although Notch and APP are both cleaved by $\gamma$-secretase, the specificity of cleavage seems to be quite different. There is no primary sequence similarity between the $\gamma$-secretase cleavage sites of Notch and APP, which suggests that the enzyme may recognize a similar conformation, rather than recognizing the primary amino acid sequence. Site-directed mutagenesis of the mouse Notch1 cleavage site has shown that a single amino acid substitution at residue 1744 can inhibit cleavage dramatically (Schroeter et al. 1998; Huppert et al. 2000). In contrast, mutations around the APP cleavage site alter the ratio of $A \beta 40$ to $A \beta 42$ but none lead to a dramatic decrease in $\gamma$-secretase cleavage. It is not clear whether the residual NICD detected is cells that express $\mathrm{Val}^{1744}$ mutant Notch protein results from cleavage at alternative sites in a manner that is analogous to $A \beta 40 /$
Aß42 production from APP. Several scenarios were envisioned to explain these differences. First, different $\gamma$-secretase activities may catalyze these reactions. An inhibitor has been reported that shows significant differences in its capacity to inhibit APP and Notch (Molinoff et al. 2000). However, the inhibition coefficient of many $\gamma$-secretase inhibitors for Notch and APP proteolysis is similar (De Strooper et al. 1999), arguing against this possibility. A possible alternative explanation evokes the existence of specific adapters that impose a specific, rigid conformation on the Notch $/ \gamma$-secretase complex, thus determining the cleavage site, whereas other adapters allow a more permissive conformation of $\gamma$-secretase with APP. This latter model is consistent with the differential inhibition of Notch and APP cleavage by D257A mutation in PS1 (Capell et al. 2000) and may offer hope for successful pharmacological distinction between Notch and APP proteolysis via targeting of adapter/enzyme interface. It is worth reemphasizing that, because Notch signaling is active in the adult (e.g., in renewing epithelia, in the modulation of neuronal plasticity, and in hematopoiesis), blocking $\gamma$-secretase activity could have undesirable consequences even if Notch and APP are the only substrates of $\gamma$-secretase.

Another unsolved mystery relates to the proteolysis of truncated proteins that are thought to be preferred substrates of $\gamma$-secretase. Cleavage of both APP C99/C83 and $\mathrm{N}^{\Delta \mathrm{E}}$ by PS appears to be regulated. In the case of Notch, cleavage by PS is activated by ligand binding and most likely occurs at the cell surface. However, PS/ Notch coimmunoprecipitation has shown that PS can bind Notch early in the secretory pathway and that it is transported with Notch to the cell surface (Ray et al. 1999a). It has been postulated that ligand binding followed by S2 cleavage may lead to a change in Notch conformation that allows PS to release NICD (Mumm et al. 2000; Parks et al. 2000). However, the constitutively active form of Notch, $\mathrm{N}^{\Delta \mathrm{E}}$, also binds to PS early in the secretory pathway (Ray et al. 1999a), but is not cleaved to form NICD until it exits the trans-Golgi (Schroeter et al. 1998). PS also binds immature APP, presumably in the $\mathrm{ER}$, but $\gamma$-secretase cleaves APP in the trans-Golgi network only after $\alpha$ - or $\beta$-secretase cleavage of full length APP. It is possible that $\alpha$ - or $\beta$-secretase cleavage of APP may also cause a conformational change that enables subsequent cleavage by $\gamma$-secretase. C99, the APP equivalent of $\mathrm{N}^{\Delta \mathrm{E}}$, can be coimmunoprecipitated with PS from the ER, however $\gamma$-secretase cleaves C99/C83 in the trans-Golgi network, similar to full-length APP (Xia et al. 2000). These observations suggest that formation of the substrate/PS complex is not sufficient for cleavage to occur. One possibility is that an unknown negative regulator (or regulators) blocks PS cleavage of substrates until the complex is in the correct cellular location. Alternatively, Notch, APP, or PS may not be in the proper TM conformation, or PS may not be cleaved in these complexes until it reaches the proper location.

In summary, the finding that PS are $\gamma$-secretases provides further support for the $\beta$-amyloid hypothesis of $A D$ pathogenesis. We now know that FAD mutations occur 
in the substrate (APP) and one of the enzymes ( $\gamma$-secretases) that generates $A \beta$, and that all mutations result in elevated levels of $A \beta 42$, a highly amyloidogenic form of the $A \beta$ peptide. This suggests that other FAD genes may include molecules that cleave APP to generate $A \beta$ and those that are involved in the clearance or degradation of $\mathrm{A} \beta$. The effectiveness of $\gamma$-secretase (or $\beta$-secretase) inhibitors as a treatment for AD will depend on how many $\gamma$-secretase substrates other than Notch exist and if inhibitors can be developed that decrease $A \beta$ production without causing severe side effects because of the inhibitory effects on other substrates. The biological importance of proteolysis is well-documented, from formation of neuropeptides and antigen presentation through zymogen activation, NFKB signaling and ubiquitin-mediated proteolysis. The general importance to biology of the PS story is the emergence of a new signaling paradigm, regulated intramembrane proteolysis (RIP; Brown et al. 2000), which utilizes a novel class of enzymes and is widely used in development from fertilization to senescence. This method of signaling utilizes fragments of dual address proteins instead of secondary messengers, with one address sending the protein to a cellular site where a stimulus (e.g., ligand binding) results in proteolysis and translocation to a second cellular site-in the case of Notch and SREBP, the nucleus. How many other as yet unidentified dual address substrates are cleaved to release signaling molecules? Are serine and cysteine ICliPs to be discovered next? It is impossible to predict, but at the pace of current research in this field it will not be long before we know the answers to many of these questions.

\section{Acknowledgments}

We thank members of our laboratories for multiple discussions leading to the ideas unveiled here. Special thanks to Drs. Haass, Steiner, Seiffert, and Thinakaran for sharing unpublished observations and to the reviewers for their helpful and insightful comments that improved the manuscript. R.K. is supported by NIH grant GM55479 and Alzheimer Association RG991516; A.G. is supported by NIH grant AG17050 and American Health Assistance Foundation.

\section{Note}

A novel protein, nicastrin (Yu et al. 2000b), a type I transmembrane glycoprotein, binds to the $\mathrm{C}$-terminal derivatives of APP and modulates generation of $A \beta$. The evidence suggests that nicastrin (Aph-2 in C. elegans), may be an integral component of a putative multimeric complex (the "secretasome") required for intramembrane proteolysis of both APP and Notch (Yu et al. 2000b). Investigation of Aph-2 function in C. elegans previously established Aph-2 as a novel member of the Notch signaling pathway, however, chimeric analysis suggests that Aph-2 can act non-cell autonomously in either the signaling or the receiving cell (Goutte et al. 2000), a result potentially in conflict with the secretasome proposal made by Yu et al. (2000b).

\section{References}

Artavanis-Tsakonas, S., Rand, M.D., and Lake, R.J. 1999. Notch signaling: Cell fate control and signal integration in devel- opment.. Science 284: 770-776.

Baumeister, R., Leimer, U., Zweckbronner, I., Jakubek, C., Grunberg, J., and Haass, C. 1997. Human presenilin-1, but not familial Alzheimer's disease (FAD) mutants, facilitate Caenorhabditis elegans Notch signalling independently of proteolytic processing. Genes Funct. 1: 149-159.

Berezovska, O., Xia, M.Q., Page, K., Wasco, W., Tanzi, R.E., and Hyman, B.T. 1997. Developmental regulation of presenilin mRNA expression parallels Notch expression. I. Neuropathol. Exp. Neurol. 56: 40-44.

Brou, C., Logeat, F., Gupta, N., Bessia, C., LeBail, O., Doedens, J.R., Cumano, A., Roux, P., Black, R.A., and Israel, A. 2000. A novel proteolytic cleavage involved in notch signaling: The role of the disintegrin-metalloprotease TACE. Mol. Cell 5: 207-216.

Brown, M.S., Ye, J., Rawson, R.B., and Goldstein, J.L. 2000. Regulated intramembrane proteolysis: A control mechanism conserved from bacteria to humans includes the SREBPs (sterol regulatory element-binding proteins), transmembrane proteins of the ER whose cytosolic. Cell 100: 391-398.

Buxbaum, J.D., Liu, K.N., Luo, Y.X., Slack, J.L., Stocking, K.L., Peschon, J.J., Johnson, R.S., Castner, B.J., Cerretti, D.P., and Black, R.A. 1998. Evidence that tumor necrosis factor $\alpha$ converting enzyme is involved in regulated $\alpha$-secretase cleavage of the Alzheimer amyloid protein precursor. J. Biol. Chem. 273: 27765-27767.

Capell, A., Steiner, H., Romig, H., Keck, S., Baader, M., Grim, M.G., Baumeister, R., and Haass, C. 2000. Presenilin-1 differentially facilitates endoproteolysis of the $\beta$-amyloid precursor protein and notch. Nat. Cell Biol. 2: 205-211.

de la Pompa, J.L., Wakeham, A., Correia, K.M., Samper, E., Brown, S., Aguilera, R.J., Nakano, T., Honjo, T., Mak, T.W., Rossant, J., et al. 1997. Conservation of the Notch signalling pathway in mammalian neurogenesis. Development 124: 1139-1148.

De Strooper, B. and Annaert, W. 2000. Proteolytic processing and cell biological functions of the amyloid precursor protein. J. Cell Sci. 113: 1857-1870.

De Strooper, B., Saftig, P., Craessaerts, K., Vanderstichele, H., Guhde, G., Annaert, W., Vonfigura, K., and Vanleuven, F. 1998. Deficiency of presenilin-1 inhibits the normal cleavage of amyloid precursor protein. Nature 391: 387-390.

De Strooper, B., Annaert, W., Cupers, P., Saftig, P., Craessaerts, K., Mumm, J.S., Schroeter, E.H., Schrijvers, V., Wolfe, M.S., Ray, W.J., et al. 1999. A presenilin-1-dependent $\gamma$-secretaselike protease mediates release of Notch intracellular domain. Nature 398: 518-522.

Doan, A., Thinakaran, G., Borchelt, D.R., Slunt, H.H., Ratovitsky, T., Podlisny, M., Selkoe, D.J., Seeger, M., Gandy, S.E., Price, D.L., et al. 1996. Protein topology of presenilin 1. Neuron 170: 1023-1030.

Donoviel, D.B., Hadjantonakis, A.K., Ikeda, M., Zheng, H., Hyslop, P.S., and Bernstein, A. 1999. Mice lacking both presenilin genes exhibit early embryonic patterning defects. Genes \& Dev. 13: 2801-2810.

Esler, W.P., Kimberly, T.W., Ostaszewski, B.L., Diehl, T.S., Moore, C.L., Tsai, J.-Y., Rahmati, T., Xia, W., Selkoe, D.J., and Wolfe, M.S. 2000. Transition-state analogue inhibitors of $\gamma$-secretase bind directly to presenilin-1. Nat. Cell Biol. 2: $428-434$.

Friedlander, R., Jarosch, E., Urban, J., Volkwein, C., and Sommer, T. 2000. A regulatory link between ER-associated protein degradation and the unfolded-protein response. Nat. Cell Biol. 2: 379-384.

Goutte, C., Hepler, W., Mickey, K.M., and Priess, J.R. 2000. aph-2 encodes a novel extracellular protein required for GLP- 
1-mediated signaling. Development 127: 2481-2492.

Greenwald, I. 1994. Structure/function studies of lin-12/Notch proteins. Curr. Opin. Genet. Dev. 4: 556-562.

Haass, C. and Baumeister, R. 1999. The biological and pathological function of presenilin proteins-simple cell systems and a worm in Alzheimer's disease research. Eur. Arch. Psych. Clin. Neurosci. 249: 23-37.

Herreman, A., Hartmann, D., Annaert, W., Saftig, P., Craessaerts, K., Serneels, L., Umans, L., Schrijvers, V., Checler, F., Vanderstichele, H., et al. 1999. Presenilin 2 deficiency causes a mild pulmonary phenotype and no changes in amyloid precursor protein processing but enhances the embryonic lethal phenotype of presenilin 1 deficiency. Proc. Natl. Acad. Sci. 96: 11872-11877.

Herreman, A., Serneels, L., Annaert, W., Collen, D., Schoonjans, L., and De Strooper, B. 2000. Total inactivation of $\gamma$-secretase activity in presenilin-deficient embryonic stem cells. Nat. Cell Biol. 2: 461-462.

Huppert, S., Le, A., Schroeter, E.H., Mumm, S.J., Saxena, M.T., Milner, A.L., and Kopan, R. 2000. Embryonic lethality in mice homozygous for a processing deficient Notch1 allele. Nature 405: 966-970.

Hussain, I., Powell, D., Howlett, D.R., Tew, D.G., Meek, T.D., Chapman, C., Gloger, I.S., Murphy, K.E., Southan, C.D., Ryan, D.M., et al. 1999. Identification of a novel aspartic protease (Asp 2) as $\beta$-secretase. Mol. Cell. Neurosci. 14: 419427.

Katayama, T., Imaizumi, K., Sato, N., Miyoshi, K., Kudo, T., Hitomi, J., Morihara, T., Yoneda, T., Gomi, F., Mori, Y., et al. 1999. Presenilin-1 mutations downregulate the signalling pathway of the unfolded-protein response. Nat. Cell Biol. 1: 479-485.

Kidd, S., Lieber, T., and Young, M.W. 1998. Ligand-induced cleavage and regulation of nuclear entry of Notch in Drosophila melanogaster embryos. Genes \& Dev. 12: $3728-3740$.

Lammich, S., Kojro, E., Postina, R., Gilbert, S., Pfeiffer, R., Jasionowski, M., Haass, C., and Fahrenholz, F. 1999. Constitutive and regulated $\alpha$-secretase cleavage of Alzheimer's amyloid precursor protein by a disintegrin metalloprotease. Proc. Nat1. Acad. Sci. 96: 3922-3927.

LaPointe, C.F. and Taylor, R.K. 2000. The type 4 prepilin peptidases comprise a novel family of aspartic acid proteases. $J$. Biol. Chem. 275: 1502-1510.

Lecourtois, M. and Schweisguth, F. 1998. Indirect evidence for $\Delta$ -dependent intracellular processing of notch in Drosophila embryos. Curr. Biol. 8: 771-774.

Lee, M.K., Slunt, H.H., Martin, L.J., Thinakaran, G., Kim, G., Gandy, S.E., Seeger, M., Koo, E., Price, D.L., and Sisodia, S.S. 1996. Expression of presenilin 1 and 2 (Ps1 and Ps2) in human and murine tissues. J. Neurosci. 16: 7513-7525.

Lehmann, S., Chiesa, R., and Harris, D.A. 1997. Evidence for a six-transmembrane domain structure of presenilin 1. J. Biol. Chem. 272: 12047-12051.

Lendon, C.L., Martinez, A., Behrens, I.M., Kosik, K.S., Madrigal, L., Norton, J., Neuman, R., Myers, A., Busfield, F., Wragg, M., et al. 1997. E280A PS-1 mutation causes Alzheimer's disease but age of onset is not modified by ApoE alleles. Hum. Mutat. 10: 186-195.

Levitan, D. and Greenwald, I. 1995. Facilitation of lin-12--mediated signalling by sel-12, a Caenorhabditis elegans S182 Alzheimer's disease gene. Nature 377: 351-354.

Levitan, D., Doyle, T.G., Brousseau, D., Lee, M.K., Thinakaran, G., Slunt, H.H., Sisodia, S.S., and Greenwald, I. 1996. Assessment of normal and mutant human presenilin function in Caenorhabditis elegans. Proc. Nat1. Acad. Sci. 93: 14940-
14944.

Li, X.J. and Greenwald, I. 1996. Membrane topology of the C. elegans Sel-12 presenilin. Neuron 17: 1015-1021.

. 1997. Hop-1, a Caenorhabditis elegans presenilin, appears to be functionally redundant with Sel-12 presenilin and to facilitate Lin-12 and Glp-1 signaling. Proc. Natl. Acad. Sci. 94: 12204-12209.

- 1998. Additional evidence for an eight-transmembranedomain topology for Caenorhabditis elegans and human presenilins. Proc. Nat1. Acad. Sci. 95: 7109-7114.

Li, Y.M., Lai, M.T., Xu, M., Huang, Q., DiMuzio-Mower, J., Sardana, M.K., Shi, X.P., Yin, K.C., Shafer, J.A., and Gardell, S.J. 2000a. presenilin 1 is linked with $\gamma$-secretase activity in the detergent solubilized state. Proc. Natl. Acad. Sci. 97: 6138-6143.

Li, Y.M., Xu, M., Lai, M.T., Huang, Q., Castro, J.L., DiMuzioMower, J., Harrison, T., Lellis, C., Nadin, A., Neduvelil, J.G., et al. 2000b. Photoactivated $\gamma$-secretase inhibitors directed to the active site covalently label presenilin 1. Nature 405: 689-694.

Lin, X., Koelsch, G., Wu, S., Downs, D., Dashti, A., and Tang, J. 2000. Human aspartic protease memapsin 2 cleaves the $\beta$-secretase site of $\beta$-amyloid precursor protein. Proc. Natl. Acad. Sci. 97: 1456-1460.

Milner, L.A. and Bigas, A. 1999. Notch as a mediator of cell fate determination in hematopoiesis: Evidence and speculation. Blood 93: 2431-2448.

Molinoff, B.P., Felsenstein, M.K., Smith, W.D., and Barten, M.D. 2000. Ab modulation: the next generation of AD therapeutics. Neurobiol. Aging 21: S136.

Mumm, J.S. and Kopan, R. 2000. Notch signaling: From the outside in. Dev. Biol. (in press).

Mumm, J.S., Schroeter, E.H., Saxena, M.T., Griesemer, A., Tian, X., Pan, D.J., Ray, W.J., and Kopan, R. 2000. A ligand-induced extracellular cleavage regulates $\gamma$-secretase-like proteolytic activation of Notch1. Mol. Cell 5: 197-206.

Nakai, T., Yamasaki, A., Sakaguchi, M., Kosaka, K., Mihara, K., Amaya, Y., and Miura, S. 1999. Membrane topology of Alzheimer's disease-related presenilin 1. Evidence for the existence of a molecular species with a seven membrane-spanning and one membrane-embedded structure. J. Biol. Chem. 274: 23647-23658.

Naruse, S., Thinakaran, G., Luo, J.J., Kusiak, J.W., Tomita, T., Iwatsubo, T., Qian, X.Z., Ginty, D.D., Price, D.L., Borchelt, D.R., et al. 1998. Effects of PS1 deficiency on membrane protein trafficking in neurons. Neuron 21: 1213-1221.

Nishimura, M., Yu, G., Levesque, G., Zhang, D.M., Ruel, L., Chen, F., Milman, P., Holmes, E., Liang, Y., Kawarai, T., et al. 1999. Presenilin mutations associated with Alzheimer disease cause defective intracellular trafficking of betacatenin, a component of the presenilin protein complex. Nat. Med. 5: 164-169.

Niwa, M., Sidrauski, C., Kaufman, R.J., and Walter, P. 1999. A role for presenilin-1 in nuclear accumulation of Ire1 fragments and induction of the mammalian unfolded protein response. Cell 99: 691-702.

Oka, C., Nakano, T., Wakeham, A., Delapompa, J.L., Mori, C., Sakai, T., Okazaki, S., Kawaichi, M., Shiota, K., Mak, T.W., et al. 1995. Disruption of the mouse Rbp-J(k) gene results in early embryonic death. Development 121:32913301.

Parks, A.L., Klueg, K.M., Stout, J.R., and Muskavitch, M.A. 2000. Ligand endocytosis drives receptor dissociation and activation in the Notch pathway. Development 127: 13731385.

Ray, W.J., Ashall, F., and Goate, A.M. 1998. Molecular patho- 
genesis of sporadic and familial forms of Alzheimer's disease. Mol. Med. Today 4: 151-157.

Ray, W.J., Yao, M., Mumm, J., Schroeter, E.H., Saftig, P., Wolfe, M., Selkoe, D.J., Kopan, R., and Goate, A.M. 1999a. Cell surface presenilin-1 participates in the $\gamma$-secretase-like proteolysis of notch. J. Biol. Chem. 274: 36801-36807.

Ray, W.J., Yao, M., Nowotny, P., Mumm, J., Zhang, W.J., Wu, J.Y., Kopan, R., and Goate, A.M. 1999b. Evidence for a physical interaction between presenilin and Notch. Proc. Nat1. Acad. Sci. 96: 3263-3268.

Sato, N., Urano, F., Leem, J.-Y., Kim, S.-H., Li, M., Donoviel, D., Bernstein, A., Lee, A.S., Ron, D., Veselits, M.L., et al. 2000. Upregulation of $\mathrm{BiP}$ and $\mathrm{CHOP}$ by the unfolded-protein response is independent of Presenilin expression. Nat. Cell Biol. (in press).

Schroeter, E.H., Kisslinger, J.A., and Kopan, R. 1998. Notch-1 signalling requires ligand-induced proteolytic release of intracellular domain . Nature 393: 382-386.

Seiffert, D., Bradley, D.J., Rominger, M.C., Rominger, H.D., Yang, F., Meredith, E.J.J., Wang, Q., Roach, H.A., Thompson, A.L., Spitz, M.S., et al. 2000. Presenilin-1 and 2 are molecular targets for $\gamma$-secretase inhibitors. J. Biol. Chem. (in press).

Selkoe, D.J. 1998. The cell biology of $\beta$-amyloid precursor protein and presenilin in Alzheimer's disease. Trends Cell Biol. 8: 447-453.

Selkoe, D.J. 1999. Translating cell biology into therapeutic advances in Alzheimer's disease. Nature 399: A23-A31.

Shen, J., Bronson, R.T., Chen, D.F., Xia, W., Selkoe, D.J., and Tonegawa, S. 1997. Skeletal and CNS defects in presenilin1-deficient mice. Cell 89: 629-639.

Sinha, S., Anderson, J.P., Barbour, R., Basi, G.S., Caccavello, R., Davis, D., Doan, M., Dovey, H.F., Frigon, N., Hong, J., et al. 1999. Purification and cloning of amyloid precursor protein $\beta$-secretase from human brain. Nature 402: 537-540.

Song, W.H., Nadeau, P., Yuan, M.L., Yang, X.D., Shen, J., and Yankner, B.A. 1999. Proteolytic release and nuclear translocation of Notch-1 are induced by presenilin-1 and impaired by pathogenic presenilin-1 mutations. Proc. Natl. Acad. Sci. 96: 6959-6963.

Steiner, H., Duff, K., Capell, A., Romig, H., Grim, M.G., Lincoln, S., Hardy, J., Yu, X., Picciano, M., Fechteler, K., et al. 1999. A loss of function mutation of presenilin-2 interferes with amyloid $\beta$-peptide production and notch signaling. J. Biol. Chem. 274: 28669-28673.

Struhl, G. and Adachi, A. 1998. Nuclear access and action of Notch in vivo. Cell 93: 649-660.

Struhl, G. and Greenwald, I. 1999. Presenilin is required for activity and nuclear access of Notch in Drosophila. Nature 398: $522-525$.

Thinakaran, G., Borchelt, D.R., Lee, M.K., Slunt, H.H., Spitzer, L., Kim, G., Ratovitsky, T., Davenport, F., Nordstedt, C., Seeger, M., et al. 1996. Endoproteolysis of presenilin 1 and accumulation of processed derivatives in vivo. Neuron 17: 181-190.

Travers, K.J., Patil, C.K., Wodicka, L., Lockhart, D.J., Weissman, J.S., and Walter, P. 2000. Functional and genomic analyses reveal an essential coordination between the unfolded protein response and ER-associated degradation. Cell 101: 249258

Vassar, R., Bennett, B.D., Babu-Khan, S., Kahn, S., Mendiaz, E.A., Denis, P., Teplow, D.B., Ross, S., Amarante, P., Loeloff, R., et al. 1999. $\beta$-secretase cleavage of Alzheimer's amyloid precursor protein by the transmembrane aspartic protease BACE. Science 286: 735-741.

von Koch, C.S., Zheng, H., Chen, H., Trumbauer, M., Thinakaran, G., van der Ploeg, L.H., Price, D.L., and Sisodia,
S.S. 1997. Generation of APLP2 KO mice and early postnatal lethality in APLP2/APP double KO mice. Neurobiol. Aging 18: 661-669.

Wang, X.Z., Harding, H.P., Zhang, Y.H., Jolicoeur, E.M., Kuroda, M., and Ron, D. 1998. Cloning of mammalian Ire1 reveals diversity in the ER stress responses. EMBO $J$. 17: 5708-5717.

Westlund, B., Parry, D., Clover, R., Basson, M., and Johnson, C.D. 1999. Reverse genetic analysis of Caenorhabditis elegans presenilins reveals redundant but unequal roles for sel-12 and hop-1 in Notch-pathway signaling. Proc. Nat1. Acad. of Sci. 96: 2497-2502.

Wolfe, M.S., Citron, M., Diehl, T.S., Xia, W., Donkor, I.O., and Selkoe, D.J. 1998. A substrate-based difluoro ketone selectively inhibits Alzheimer's $\gamma$-secretase activity. I. Med. Chem. 41: 6-9.

Wolfe, M.S., De los Angeles, J., Miller, D.D., Xia, W., and Selkoe, D.J. 1999a. Are presenilins intramembrane-cleaving proteases? Implications for the molecular mechanism of Alzheimer's disease. Biochemistry 38: 11223-11230.

Wolfe, M.S., Xia, W., Moore, C.L., Leatherwood, D.D., Ostaszewski, B., Rahmati, T., Donkor, I.O., and Selkoe, D.J. 1999b. Peptidomimetic probes and molecular modeling sug gest that Alzheimer's $\gamma$-secretase is an intramembranecleaving aspartyl protease. Biochemistry 38: 4720-4277.

Wolfe, M.S., Xia, W., Ostaszewski, B.L., Diehl, T.S., Kimberly, W.T., and Selkoe, D.J. 1999c. Two transmembrane aspartates in presenilin-1 required for presenilin endoproteolysis and gamma-secretase activity. Nature 398: 513-517.

Wong, P.C., Zheng, H., Chen, H., Becher, M.W., Sirinathsinghji, D.J.S., Trumbauer, M.E., Chen, H.Y., Price, D.L., Van der Ploeg, L.H.T., and Sisodia, S.S. 1997. Presenlin 1 is required for Notch 1 and Dll 1 expression in the paraxial mesoderm. Nature 387: 288-292.

Wu, J.Y. and Rao, Y. 1999. Fringe: Defining borders by regulating the notch pathway. Curr. Opin. Neurobiol. 9:537543.

Xia, W., Ray, W.J., Ostaszewski, B., Rahmati, T., Kimberly, W.T., Wolfe, M., Zhang, J., Goate, A.M., and Selkoe, D. 2000. Complex formation of presenilin with APP C-terminal fragments at sites of $A \beta$ generation: Evidence for direct involvement of presenilin in $\gamma$-secretase activity. Proc. Nat1. Acad. Sci. 97: 9229-9303.

Yan, R., Bienkowski, M.J., Shuck, M.E., Miao, H., Tory, M.C., Pauley, A.M., Brashier, J.R., Stratman, N.C., Mathews, W.R., Buhl, A.E., et al. 1999. Membrane-anchored aspartyl protease with Alzheimer's disease $\beta$-secretase activity. Nature 402: 533-537.

Ye, Y.H., Lukinova, N., and Fortini, M.E. 1999. Neurogenic phenotypes and altered Notch processing in Drosophila Presenilin mutants. Nature 398: 525-529.

Yu, G., Chen, F., Nishimura, M., Steiner, H., Tandon, A., Kawarai, T., Arawaka, S., Supala, A., Song, Y.-Q., Rogaeva, E., et al. 2000a. Mutation of conserved aspartates affect maturation of both aspartate-mutant and endogenous presenilin 1 and presenilin 2 complexes. J. Biol. Chem. 275: 27348 27353.

Yu, G., Nishimura, M., Arawaka, S., Levitan, D., Zhang, L., Tandon, A., Song, Y.-Q., Rogaeva, E., Chen, F., Kawarai, T., et al. 2000b. A novel protein (Nicastrin) modulates presenilin-mediated Notch/Glp1 and APP preocessing. Nature 407: 48-54.

Zhang, Z., Nadeau, P., Song, W., Donoviel, D., Yuan, M., Bernstein, A., and Yankner, B.A. 2000. Presenilins are required for $\gamma$-secretase cleavage of $\beta$-APP and transmembrane cleavage of Notch-1. Nat. Cell Biol. 2: 463-465. 


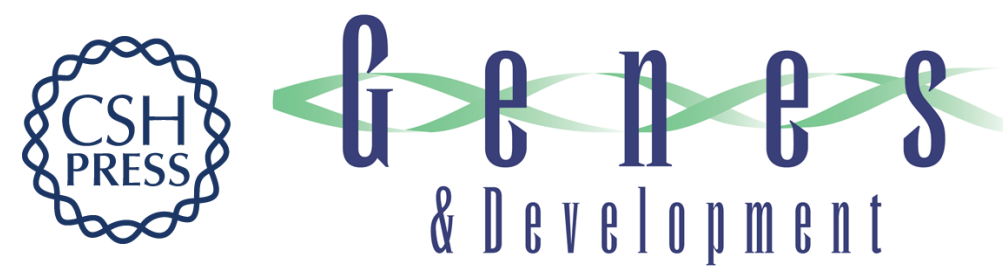

\section{A common enzyme connects Notch signaling and Alzheimer's disease}

Raphael Kopan and Alison Goate

Genes Dev. 2000, 14:

Access the most recent version at doi:10.1101/gad.836900

References This article cites 75 articles, 29 of which can be accessed free at:

http://genesdev.cshlp.org/content/14/22/2799.full.html\#ref-list-1

License

Email Alerting Receive free email alerts when new articles cite this article - sign up in the box at the top

Service right corner of the article or click here.

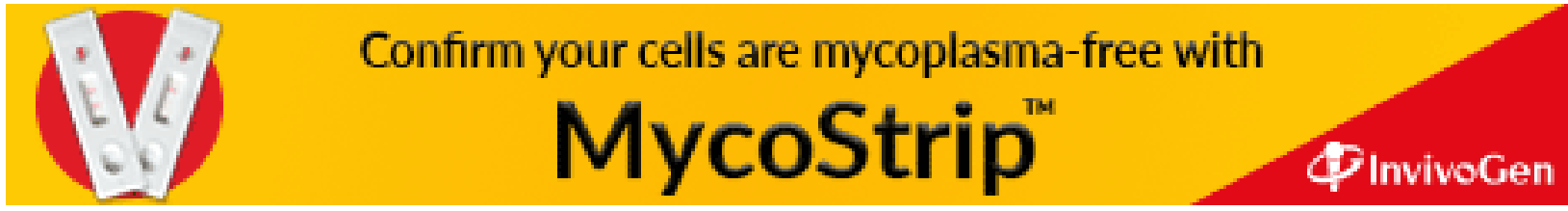

